\title{
Stochastic Petri Net Based Modeling of Emergency Medical Rescue Processes During Earthquakes*
}

\author{
SUN Huali · LIU Jiaguo · HAN Ziqiang · JIANG Juan
}

DOI: $10.1007 / \mathrm{s} 11424-020-9139-3$

Received: 25 April 2019 / Revised: 22 February 2020

(C)The Editorial Office of JSSC \& Springer-Verlag GmbH Germany 2020

\begin{abstract}
The post-disaster emergency medical rescue (EMR) is critical for people's lives. This paper presents a stochastic Petri net (SPN) model based on the process of the rescue structure and a Markov chain model (MC), which is applied to the optimization of the EMR process, with the aim of identifying the key activities of EMR. An isomorphic MC model is developed for measuring and evaluating the time performance of the EMR process during earthquakes with the data of the 2008 Wenchuan earthquake. This paper provides a mathematical approach to simulate the process and to evaluate the efficiency of EMR. Simultaneously, the expressions of the steady state probabilities of this system under various states are obtained based on the MC, and the variations of the probabilities are analyzed by changing the firing rates for every transition. Based on the concrete data of the event, the authors find the most time consuming and critical activities for EMR decisions. The model results show that the key activities can improve the efficiency of medical rescue, providing decision-makers with rescue strategies during the large scale earthquake.
\end{abstract}

Keywords Earthquake disaster, emergency medical rescue, Markov chain, stochastic petri net.

\section{Introduction}

China lies on the Eurasian plate, bordering the Pacific plate and the Indian Ocean Plate. This geographical location has resulted in the occurrence of a large number of seismic phenomena pertaining to the plate movement, as well as heavy economic losses ${ }^{[1,2]}$. For example,

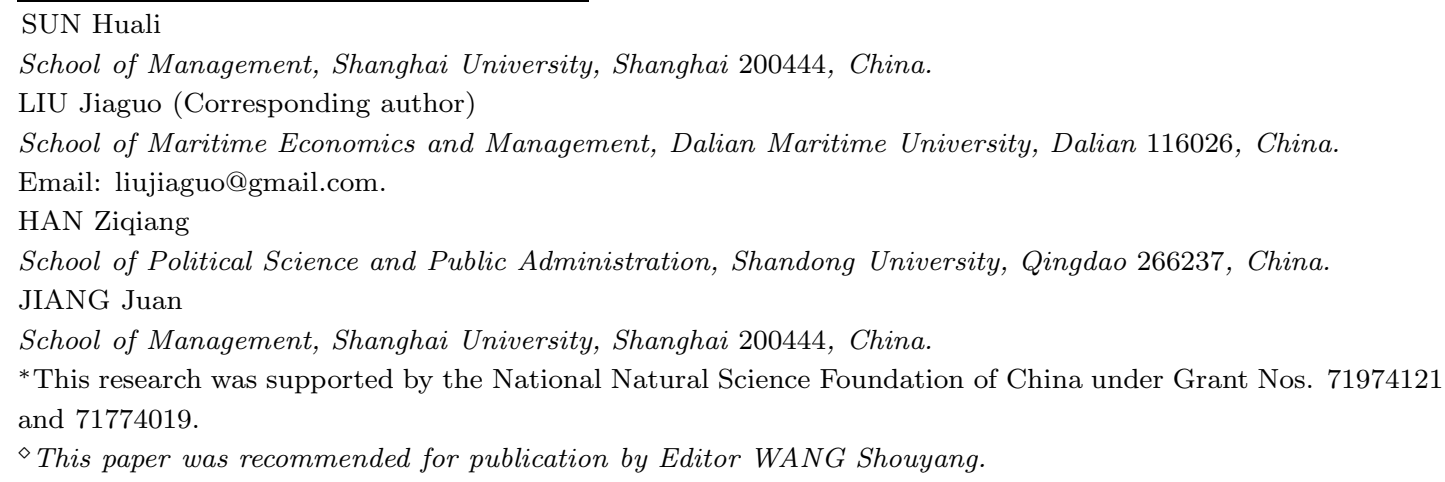


the magnitude 7.9 earthquake that struck the Sichuan Province in China in May 2008 resulted in direct economic losses of 850 billion yuan ${ }^{[3]}$ and left 375,000 people injured, 87,150 people missing or dead and a total of 105 million people affected ${ }^{[4]}$. In 2017, Jiuzhaigou was hit by a magnitude 7 earthquake that affected 17 townships and 120 villages to varying degrees. 25 people were killed and 525 were injured in the earthquake ${ }^{[5]}$. Therefore, it is necessary to establish an earthquake emergency preparedness and response framework and improve the efficiency of emergency rescue to reduce personal injury and direct economic losses. In addition, this policy is one of China basic national policies pertaining to the development of earthquake prevention and disaster management.

Until now, many studies have extensively discussed earthquake emergency response ${ }^{[6,7]}$. Usually, emergency organizations dispatch emergency rescue teams and medical relief materials $^{[8-10]}$. However, earthquake emergency rescue can not only help solve the problem of coordination between rescue organizations but also help improve the efficiency of earthquake rescue, strengthen the organization of rescue activities, and reduce loss ${ }^{[11]}$. Therefore, it is necessary to enhance the evaluation and optimize the understanding of the coordination process of earthquake emergency rescue organizations.

In general, based on the rescue process of major earthquake events in recent years, our research aims to analyze the performance of earthquake emergency medical rescue (EMR) using quantitative analysis and to determine the key activities to improve the efficiency and service level of earthquake EMR. Regarding the emergency rescue process, existing studies have used multiple model-based methods to evaluate and optimize the flow of different types of rescue processes ${ }^{[12,13]}$. Petri nets have long demonstrated the dominance of their application in different fields as an effective approach to portray workflows ${ }^{[14,15]}$. Petri nets, as a powerful process modeling tool, can dynamically represent the coupling relationship in a system and accurately represent the behavior in the system ${ }^{[16]}$. According to the research purpose, Petri net content can be divided into different forms such as coloring networks, stochastic networks, and object networks. Among these forms, the Petri net incorporating the time factor (stochastic activity networks: Structure, behavior, and application) can allow the graphic description of the dynamic behavior of a system network ${ }^{[17]}$. Therefore, we applied the stochastic Petri net model to the EMR process in the disaster area after an earthquake, to solve the unreasonable aspects of the video memory process, increase the coordination degree of the rescue conducted by earthquake emergency medical organizations and enhance the efficiency of EMR.

Correspondingly, the structure of the remaining article is as follows. In Section 2, we provide a literature review of the relevant aspects to provide a theoretical basis for research content. In Section 3, we describe the methodology and introduce the process structure of earthquake EMR obtained via Petri net modeling analysis. In Section 4, we introduce the case analysis of the earthquake disaster that occurred on May 12, 2008, and optimize the EMR process of the earthquake. In Section 5, we discuss the results and provide suggestions for future research. This paper has two novel aspects. First, the earthquake EMR is analyzed from a systems perspective. The general earthquake rescue process is summarized according to the major earthquake disasters in China in recent years (Subsection 2.2). Second, based on the results of 
the model analysis, the bottleneck points in the process of earthquake EMR are considered as an example and several suggestions are proposed (Section 4).

\section{Related Literature}

Earthquakes, as a type of natural disaster, have the characteristics of low probability and sudden occurrence. In the immediate aftermath of an earthquake, people are unable to organize effective resilience actions in a short period, which may lead to more considerable damage. Therefore, in the event of an earthquake, two links, namely, emergency response and medical rescue exist. At this stage, the rescue department should continuously assess the extent of the damage due to the earthquake and coordinate the response of the equipment and materials to reach the locations in which they are needed most ${ }^{[18]}$. In other words, the response is activated, and the rescue is the goal ${ }^{[19]}$. The earthquake EMR process should be optimized to improve the efficiency of the response to earthquake emergencies. Therefore, by referring to the literature and expanding existing research ideas, the literature was classified into those pertaining to the emergency rescue response process, emergency medical services, and Petri net modeling.

\subsection{Emergency Rescue Response Process}

The study of the emergency rescue response process primarily reflects the characteristics of the process. Specifically, the emergency rescue response has the characteristics of a life cycle, that is, information acquisition and effective response before the event with a focus on rescue response and rapid recovery ${ }^{[20]}$. However, the emergency response process requires a more reasonable and correct sequence of support to improve responsiveness, such as observation, orientation, decision making, act (OODA), to ensure that it can have a coupling role in the decision unit ${ }^{[21]}$. The characteristics of such an emergency rescue process often include specific decision-making problems and applications. First, in the process of emergency rescue, the acquisition of collective knowledge and information supporting emergency rescue management can effectively alleviate the shortage of basic rescue information for the rescue and relief command team and improve the efficiency of emergency decision making ${ }^{[22]}$. On this basis, we can use situational images or IDEFO type language modeling tools to build an emergency response process with a certain elasticity, describe the rescue process, help enhance the decision-making clarity of disaster response and provide a structured basis for redesigning emergency process decisions $^{[23-25]}$.

In addition, in Greece and other European countries, key elements such as emergency response methods and means, response time and timely information products have been noted to have a positive impact on emergency response to major disasters and accidents ${ }^{[26]}$.

\subsection{Emergency Medical Services}

In the face of an earthquake disaster, the number of medical rescue workers to save personnel depends on three factors, namely, response time, onsite care and transfusion of emergency medical care ${ }^{[27]}$. An effective emergency medical service system facilitates the delivery of patients with different medical classifications to the corresponding professional medical association for 
treatment in the shortest response time and transport time ${ }^{[28]}$. Similarly, as indicated by the results of Klein (2016) study, the consideration of decision making elements including patient mobility, lifesaving interventions, contextual instincts and logistics in mass casualty scenarios can accurately identify the severity and type of injury/disease per casualty, ensure that victims can obtain the suitable transport priorities and receive appropriate medical care quickly and effectively. For patients with different levels of injury, such aspects usually depend on the time efficiency of rescue transportation. Currently, two modes of transporting the wounded are used: helicopter transport and land transport. Among these, helicopter service is a limited and expensive resource, which helps improve the survival rate of severely injured people ${ }^{[29-31]}$.

\subsection{Petri Net Modeling and Optimization}

Petri nets, as a tool for modeling discrete event systems, can model and visualize behaviors including concurrency, synchronization and resource sharing. The purpose of the study is to establish different types of Petri net models, such as synchronization, timing, stochastic, colored and continuous models, which are currently applied to supply chain management ${ }^{[32]}$, industrial manufacturing process optimization ${ }^{[33,34]}$ and other aspects. Petri nets have been proved to provide a conventional method for modeling complex scenarios ${ }^{[35]}$. The application of Petri nets in the emergency management process has been researched extensively. For example, consider the problem of the efficiency of emergency resource utilization, Zhou and Genserik ${ }^{[36]}$ proposed a cooperative model involving Petri net modeling and its integration into the emergency action model queuing system to avoid conflicts caused by limited resource sharing. Based on the basic model of a Petri net, Liu, et al. ${ }^{[37]}$ designed the E-net method for emergency response processes that were constrained by resources and uncertain duration, and a case study on chlorine tank explosions was performed to validate the applicability of the model.

Although the above research helped improve the understanding of EMR response, it did not fully reveal the application of the EMR process in earthquake rescue. This aspect also reflects the importance of time and resource management and optimization in the application of earthquake emergency management ${ }^{[38]}$. Petri nets, as a powerful tool for complex process modeling, can help understand the flow of seismic emergency activities through visual graphical modeling. However, a lack of sufficient discussion exists in the current research, especially from the perspective of the complete rescue process.

By extending the existing research, this study further expands the research concepts regarding the earthquake EMR process, focusing the research perspective on the relationship between the complete EMR links, establishing the structured process model, and determining the key factors restricting the rescue efficiency. The SPN model and equivalent Markov chain of an earthquake EMR process are constructed by using the SPN model. Finally, based on the Wenchuan earthquake, the validity test and performance analysis of the model of an EMR process is performed using real data. Subsequently, the key time-consuming activities in the EMR process are clarified. This research would be helpful to the understanding of earthquake EMR activities and improving the efficiency of emergency rescue activities. 


\section{$3 \quad$ Research Methodology}

In this section, we introduce the steps to establish an EMR process and the corresponding SPN model to analyze the response process of earthquake EMR.

\subsection{Process Structure of Earthquake EMR}

According to the relevant literature ${ }^{[39-43]}$ and the data of large scale earthquakes reported in recent years, we selected certain events, including the Wenchuan earthquake and the Ya'an earthquake. The medical rescue process is an important part of emergency management, which begins with the occurrence of the disaster in the earthquake areas including the government response to emergency decision making and ends with the recovery of the wounded. In terms of the complexity of concrete situations, we did not consider the transportation of supplies and assumed that the supplies could satisfy the requirements of local rescue. According to the scenes of grading treatment ${ }^{[44]}$, the medical rescue process during an earthquake can be divided into four parts: Preparation phase, onsite rescue phase, treatment in disaster area phase and rear treatment phase.

After the occurrence of an earthquake, the central government must organize an urgent meeting and set up an emergent conduction center to launch the emergency response. Simultaneously, as the local government receives the information, they must perform preparatory work and wait for directions from the superior. When the rescue team arrives in the disaster area, the head of the site rescue must make appropriate arrangements according to the situation on the site to ensure that the operation is performed in an orderly manner. It is known that the victims have the highest opportunity to survive in a particular period of time, usually termed as the golden $72 \mathrm{~h}$. In addition, the rescue conduction center must provide feedback regarding the sufficiency of onsite rescue resources to the superior. Most importantly, hospitals must work together to transport the victims and even treat them jointly. The concrete process is illustrated in Figure 1.

\subsection{Medical Rescue Process Modeling Based on Stochastic Petri Net}

Petri nets were proposed by Carl Adam Petri in his doctoral paper. At present, PNs are extensively applied for the performance analysis and control research of discrete event dynamic systems. Usually, the flow of tokens is used to simulate a dynamic system and its activities. Subsequently, Vautherlin proposed a concept that connected the transitions with stochastic firing rates based on a Petri net, termed the stochastic Petri net $(\mathrm{SPN})^{[45]}$. In an SPN, a transition requires a certain time to occur. Generally, this time is viewed as a continuous random variable, which must be a positive real number and subject to an exponential distribution function $^{[46]}$. An SPN model is a 6-tuple. 


\section{Preparation Phase}

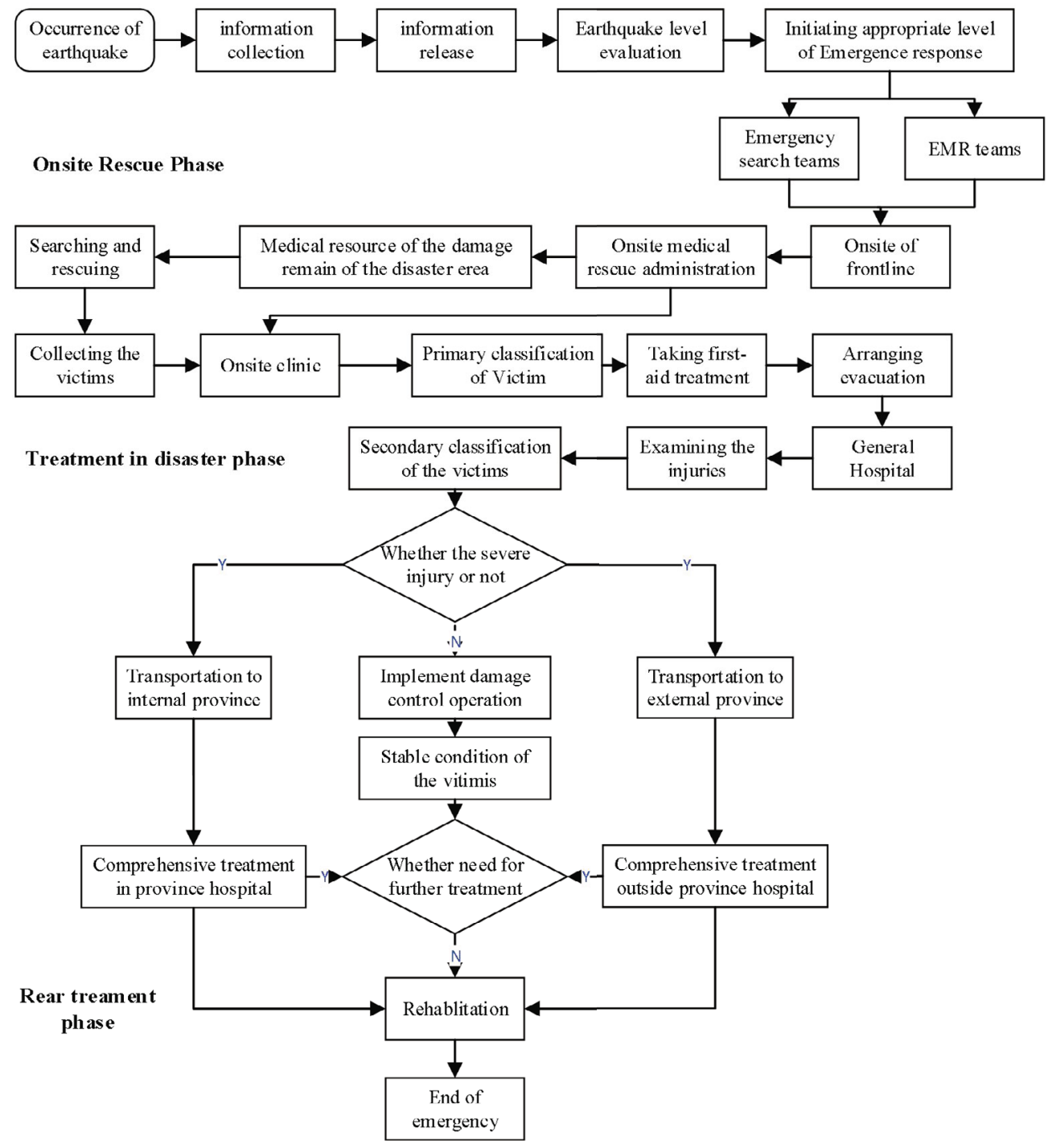

Figure 1 Emergency medical care process in an earthquake

$S P N=\left(P, T, F, W, M_{0}, \lambda\right)$, where

1) $P=\left\{p_{1}, p_{2}, \cdots, p_{n}\right\}$ refers to the finite set of places. A place $p$ is represented as a circle and denotes the resources of medical rescue. For example, $p_{2}$ denotes the message of occurrence of an earthquake.

2) $T=\left\{t_{1}, t_{2}, \cdots, t_{m}\right\}, m>0$ refers to the finite set of transitions and satisfies $P \cap T=\emptyset$. Here, $\emptyset$ is null set. A transition $t$ is represented as a rectangle and denotes the activities of medical rescue. For example, $t_{1}$ denotes the release of a message pertaining to the earthquake. 
3) $\lambda=\left\{\lambda_{1}, \lambda_{2}, \cdots, \lambda_{m}\right\}$ is the set of average firing rates of transitions, which denotes the rate of each activity in the proposed model.

4) $F$ is an ordered pair set consisting of $P$ and $T$, and it satisfies $F \subseteq(P \times T) \cup(T \times P)$. The nodes are connected through directed arcs.

5) $K$ is the capacity of a place.

6) $W$ is a weight function weighting all the arc lines. $w(p, t)$ or $w(t, p)$ are used to denote the weight of a directed arc from $t$ to $p$.

7) $M$ is the marking reflecting token distribution in all the places in a Petri net.

A transition is enabled when each input place of the net contains at least one token. For example, only when $t_{1}$ contains at least one token, indicating that the earthquake has occurred, can convey earthquake information. The firing of a transition removes one token from each input place to the corresponding output place. The distribution of tokens, called SPN marking, defines the state of the modeled process ${ }^{[47]}$. A set of places called input places exist, which can fire a transition, while other places called output places are associated with the results from a transition. The SPN structure and dynamic system properties resulting from the execution of SPN can clarify the static properties of the system. The execution requires the use of tokens and markings (denoted by dots) associated with the places. In the proposed SPN, the moving of tokens indicates the medical rescue information process. The special state of the system is generally presented by the markings of the SPN. The forward markings decide the set of all possible states of the system with a given initial state. Generally, the simulation can be viewed as a continuous-time stochastic Petri net. One transition requires a certain time delay from being generable to practical execution, which is regarded as a continuous random variable. This variable is subject to an exponential distribution. In a previous study, it has been proved that an SPN is isomorphic to a continuous-time $\mathrm{MC}^{[48]}$.

In this study, we focus on the process modeling and analysis for the earthquake medical care process. Figure 2 shows the SPN model of the earthquake medical care process. The SPN model combines all the seismic health care activities presented in Figure 1 and indicates the relationship among these activities.

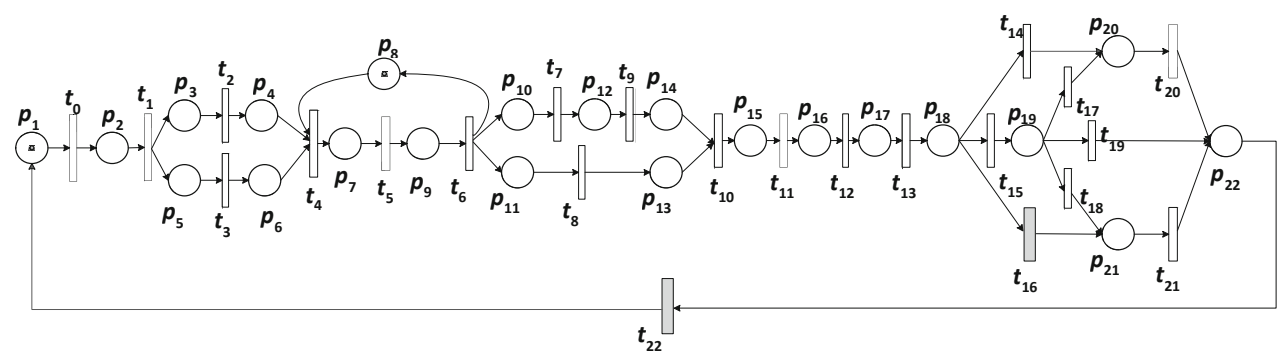

Figure 2 SPN model of the medical care process during an earthquake

In Figure 2, a place represents a situation and information, and a transition represents the activities during the medical rescue process. A total of 22 places and 23 transitions are present, and their respective definitions are presented in Tables 1 and 2 . 
Table 1 Definitions of places

\begin{tabular}{|c|c|c|c|}
\hline \multicolumn{2}{|r|}{ Places } & \multicolumn{2}{|r|}{ Places } \\
\hline$p_{1}$ & Earthquake occurrence & $p_{12}$ & The victims rescued from the debris \\
\hline$p_{2}$ & Message of earthquake occurrence & $p_{13}$ & Information of finishing onsite clinic \\
\hline$p_{3}$ & $\begin{array}{l}\text { Messages received by the provincial gov- } \\
\text { ernment }\end{array}$ & $p_{14}$ & Victims arrival to onsite clinic \\
\hline$p_{4}$ & Finished preparatory work & $p_{15}$ & Victims after primary classification \\
\hline$p_{5}$ & $\begin{array}{l}\text { Earthquake message to central govern- } \\
\text { ment }\end{array}$ & $p_{16}$ & Victims after being rescued \\
\hline$p_{6}$ & Earthquake medical care plan & $p_{17}$ & $\begin{array}{l}\text { Victims arrival at the general hospital } \\
\text { near the disaster area }\end{array}$ \\
\hline$p_{7}$ & Medical rescue scheduling information & $p_{18}$ & Victims after the second classification \\
\hline$p_{8}$ & Onsite information feedback & $p_{19}$ & Victims in a steady condition \\
\hline$p_{9}$ & $\begin{array}{l}\text { Arrival of medical rescue team at disaster } \\
\text { area }\end{array}$ & $p_{20}$ & $\begin{array}{l}\text { Information regarding accepting vic- } \\
\text { tims by comprehensive hospitals in the } \\
\text { province }\end{array}$ \\
\hline$p_{10}$ & Rescuers joining onsite medical teams & $p_{21}$ & $\begin{array}{l}\text { Information regarding accepting victims } \\
\text { by comprehensive hospitals outside the } \\
\text { province }\end{array}$ \\
\hline$p_{11}$ & People establishing onsite clinic & $p_{22}$ & Recovery of the victims \\
\hline
\end{tabular}

As shown in Figure 2, the initial marking $M_{0}=\left(p_{0}, p_{8}, p_{9}\right)$ indicates that one token is present, and it also corresponds to the situation of earthquake occurrence and onsite information feedback. Other places that are not marked correspond to the number of tokens being zero. Different transitions are employed to determine the related reachability of a marking from an initial marking of an SPN, which are listed as follows:

$$
\begin{array}{lll}
M_{1}=\left(p_{1}, p_{8}, p_{9}\right), & M_{2}=\left(p_{2}, p_{3}, p_{8}, p_{9}\right), & M_{3}=\left(p_{3}, p_{4}, p_{8}, p_{9}\right), \\
M_{4}=\left(p_{5}, p_{8}, p_{9}\right), & M_{5}=\left(p_{4}, p_{5}, p_{8}, p_{9}\right), & M_{6}=\left(p_{6}, p_{8}, p_{9}\right), \\
M_{7}=\left(p_{7}, p_{8}, p_{9}\right), & M_{8}=\left(p_{8}, p_{9}, p_{10}, p_{11}\right), & M_{9}=\left(p_{8}, p_{9}, p_{11}, p_{12}\right), \\
M_{10}=\left(p_{8}, p_{9}, p_{10}, p_{13}\right), & M_{11}=\left(p_{8}, p_{9}, p_{12}, p_{13}\right), & M_{12}=\left(p_{8}, p_{9}, p_{11}, p_{14}\right), \\
M_{13}=\left(p_{8}, p_{9}, p_{13}, p_{14}\right), & M_{14}=\left(p_{8}, p_{9}, p_{15}\right), & M_{15}=\left(p_{8}, p_{9}, p_{16}\right), \\
M_{16}=\left(p_{8}, p_{9}, p_{17}\right), & M_{17}=\left(p_{8}, p_{9}, p_{18}\right), & M_{18}=\left(p_{8}, p_{9}, p_{19}\right), \\
M_{19}=\left(p_{8}, p_{9}, p_{20}\right), & M_{20}=\left(p_{8}, p_{9}, p_{21}\right), & M_{21}=\left(p_{8}, p_{9}, p_{22}\right),
\end{array}
$$


Table 2 Definitions of transitions

\begin{tabular}{|c|c|c|c|}
\hline \multicolumn{2}{|r|}{ Transition } & \multicolumn{2}{|r|}{ Transition } \\
\hline$t_{0}$ & Emergency alarm & $t_{12}$ & $\begin{array}{l}\text { Transporting the victims to the general } \\
\text { hospital near the disaster area }\end{array}$ \\
\hline$t_{1}$ & Releasing earthquake message & $t_{13}$ & $\begin{array}{l}\text { TClassifying the victims in the general } \\
\text { hospital }\end{array}$ \\
\hline$t_{2}$ & Starting preparatory work for rescue & $t_{14}$ & $\begin{array}{l}\text { Transporting the victims to comprehen- } \\
\text { sive hospitals situated in the province }\end{array}$ \\
\hline$t_{3}$ & $\begin{array}{l}\text { Initiating the emergency medical care } \\
\text { plan }\end{array}$ & $t_{15}$ & $\begin{array}{l}\text { Rescuing the victims in the general hos- } \\
\text { pital }\end{array}$ \\
\hline$t_{4}$ & Scheduling according to the authority & $t_{16}$ & $\begin{array}{l}\text { Transporting the victims to compre- } \\
\text { hensive hospitals situated outside the } \\
\text { province }\end{array}$ \\
\hline$t_{5}$ & $\begin{array}{l}\text { Launching emergency search and rescue } \\
\text { teams }\end{array}$ & $p_{17}$ & $\begin{array}{l}\text { Delivering the victims to comprehensive } \\
\text { hospitals situated in the province }\end{array}$ \\
\hline$t_{6}$ & $\begin{array}{l}\text { Allocation of rescue teams by medical } \\
\text { conductor }\end{array}$ & $p_{18}$ & $\begin{array}{l}\text { Delivering the victims to comprehensive } \\
\text { hospitals situated outside the province }\end{array}$ \\
\hline$t_{7}$ & Onsite searching & $p_{19}$ & $\begin{array}{l}\text { Rehabilitation treatment in the general } \\
\text { hospital }\end{array}$ \\
\hline$t_{8}$ & Setting up onsite clinic & $p_{20}$ & $\begin{array}{l}\text { Rescuing the victims in the hospital situ- } \\
\text { ated in the province }\end{array}$ \\
\hline$t_{9}$ & Transporting the victims to onsite clinic & $p_{21}$ & $\begin{array}{l}\text { Rescuing the victims in the hospital situ- } \\
\text { ated outside the province }\end{array}$ \\
\hline$t_{10}$ & Classifying the victims in the onsite clinic & $p_{22}$ & Ending EMR \\
\hline$t_{11}$ & $\begin{array}{l}\text { Administering first aid treatment in the } \\
\text { disaster area }\end{array}$ & & \\
\hline
\end{tabular}

\subsubsection{Validity Analysis}

To analyze the reachability, liveness and boundedness of the SPN model, a validity analysis was performed. The determination of whether a given marking $M$ belongs to the set $M_{0}$ [ $>$ or not] is a reachability problem. If a Petri net is live, no deadlock is present in the next. If no markings are present on the nodes of the reachability graph, the SPN model is bounded ${ }^{[49]}$.

Generally, the $T$ - invariant can be used to analyze the validity of the SPN model. To ensure the reachability of marking $M$ from an initial marking of an SPN, a nonnegative integer vector solution of linear equation (1) must exist:

$$
C_{x}=0,
$$

when $x=\left(x_{1}, x_{2}, \cdots, x_{n}\right)^{\mathrm{T}}$ is a firing count vector and $C$ is an $n(m \times n)$ dimensional incidence 


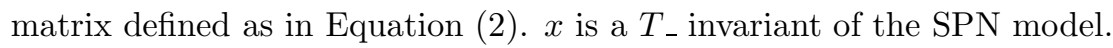

$$
\begin{aligned}
& C=\left[c_{i j}\right](1 \leq i \leq n, 1 \leq j \leq m) ; \\
& c_{i j}=W\left(t_{j}, p_{i}\right)-W\left(p_{i}, t_{j}\right),
\end{aligned}
$$

$W\left(t_{j}, p_{i}\right)$ represents the arc from transition $t_{j}$ to place $p_{i}$ and is the same as $W\left(p_{i}, t_{j}\right)$.

Following Equation (1), we can obtain the $T_{\text {_ }}$ invariant of the SPN model shown in Figure 2:

$$
\begin{aligned}
& X_{1}^{\mathrm{T}}=(1,1,1,1,1,1,1,1,1,1,1,1,1,1,0,1,0,0,0,1,0,0,1) ; \\
& X_{2}^{\mathrm{T}}=(1,1,1,1,1,1,1,1,1,1,1,1,1,1,1,0,0,0,0,0,1,0,1) ; \\
& X_{3}^{\mathrm{T}}=(1,1,1,1,1,1,1,1,1,1,1,1,1,1,0,0,1,0,0,0,0,1,1) ; \\
& X_{4}^{\mathrm{T}}=(1,1,1,1,1,1,1,1,1,1,1,1,1,1,0,1,0,1,0,0,1,0,1) ; \\
& X_{5}^{\mathrm{T}}=(1,1,1,1,1,1,1,1,1,1,1,1,1,1,0,0,0,0,1,0,0,1,1) .
\end{aligned}
$$

According to the definition of boundedness ${ }^{[50]}$, no phenomenon exists in which the resources in the SPN model overflow, which means that the SPN model is bounded. When the component of the $T$ - invariant is 1 , the related transition is considered to be fired. In contrast, a value of 0 indicates that the transition is not fired. Based on the $T_{\text {_ }}$ invariant and the reachability graph, the following conclusions can be derived: Any transition of the SPN model is likely to be fired, and our SPN model is characterized by reachability, no deadlock or liveness and boundedness.

\subsubsection{Construction of Isomorphic Markov Chain and Performance Analysis}

A Markov Chain (MC) exhibits the same performance as that of the SPN model, and it can thus help evaluate the performance of the SPN model. The reachability graph of an SPN model is isomorphic to a homogeneous MC. The performance indicators of the SPN model are calculated based on the probability distribution of the MC in the steady state. The isomorphic MC is shown in Figure 3, which is based on the SPN model shown in Figure 2. In the model, the indicator of the busy probability of the place is used as the measure of the information performance criterion. The activity performance criterion is used to describe the efficiency of the rescue activities. The utilization of the transition indicators represents the activity performance criterion in the model. The system delay time indicator is used to measure the response time criterion.

$\lambda_{1}$

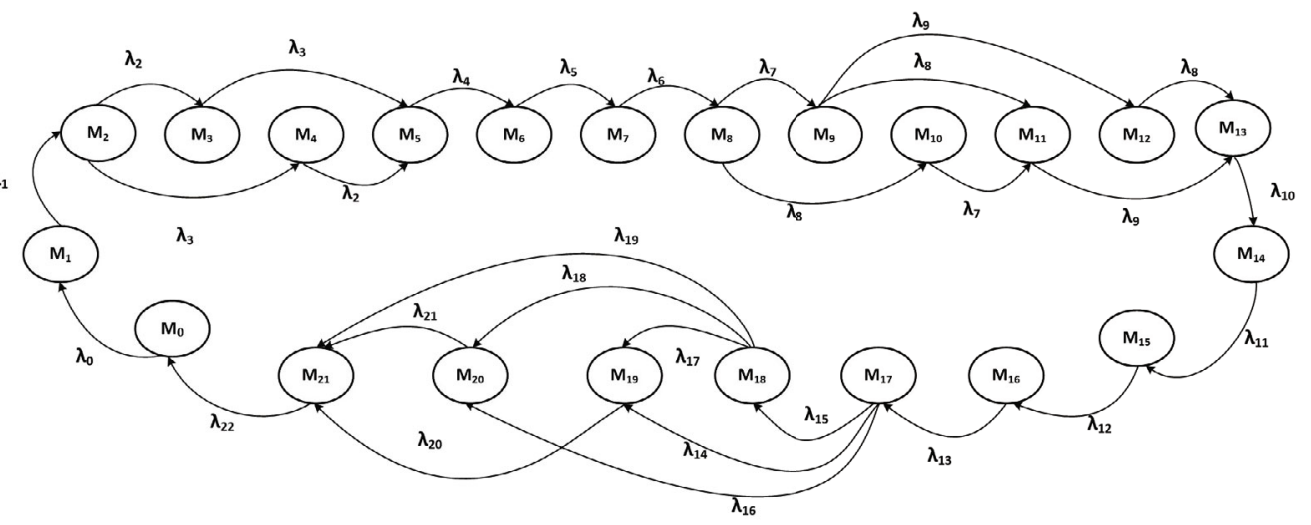

Figure 3 Isomorphic markov chain equivalent to the SPN model 
From the Markov Chain Equivalent above, the relations between the system state probability are gotten as follows:

$$
\left\{\begin{array}{l}
\lambda_{22} p\left(M_{21}\right)=\lambda_{0} p\left(M_{0}\right)=\lambda_{1} p\left(M_{1}\right) \\
\lambda_{1} p\left(M_{1}\right)=\lambda_{2} p\left(M_{2}\right)=\lambda_{3} p\left(M_{2}\right) \\
\lambda_{2} p\left(M_{2}\right)=\lambda_{3} p\left(M_{3}\right) \\
\lambda_{3} p\left(M_{2}\right)=\lambda_{2} p\left(M_{4}\right) \\
\lambda_{2} p\left(M_{4}\right)+\lambda_{3} p\left(M_{3}\right)=\lambda_{4} p\left(M_{5}\right) \\
\lambda_{4} p\left(M_{5}\right)=\lambda_{5} p\left(M_{6}\right)=\lambda_{6} p\left(M_{7}\right) \\
\lambda_{6} p\left(M_{7}\right)=\lambda_{7} p\left(M_{8}\right)+\lambda_{8} p\left(M_{8}\right) \\
\lambda_{7} p\left(M_{8}\right)=\lambda_{9} p\left(M_{9}\right)+\lambda_{8} p\left(M_{9}\right) \\
\lambda_{8} p\left(M_{8}\right)=\lambda_{7} p\left(M_{10}\right) \\
\lambda_{8} p\left(M_{9}\right)+\lambda_{7} p\left(M_{10}\right)=\lambda_{9} p\left(M_{13}\right) \\
\lambda_{9} p\left(M_{9}\right)=\lambda_{8} p\left(M_{12}\right) \\
\lambda_{8} p\left(M_{12}\right)+\lambda_{9} p\left(M_{11}\right)=\lambda_{10} p\left(M_{13}\right) \\
\lambda_{10} p\left(M_{13}\right)=\lambda_{11} p\left(M_{14}\right)=\lambda_{12} p\left(M_{15}\right)=\lambda_{13} p\left(M_{16}\right)=\left(\lambda_{15}+\lambda_{14}+\lambda 16\right) p\left(M_{17}\right) \\
\lambda_{15} p\left(M_{17}\right)=\left(\lambda_{17}+\lambda_{18}+\lambda 19\right) p\left(M_{18}\right), \\
\lambda_{17} p\left(M_{18}\right)+\lambda_{14} p\left(M_{17}\right)=\lambda_{20} p\left(M_{19}\right), \\
\lambda_{16} p\left(M_{17}\right)+\lambda_{18} p\left(M_{18}\right)=\lambda_{21} p\left(M_{20}\right), \\
\lambda_{19} p\left(M_{18}\right)+\lambda_{21} p\left(M_{20}\right)+\lambda_{20} p\left(M_{19}\right)=\lambda_{22} p\left(M_{0}\right), \\
21 \\
\sum_{i=1} p\left(M_{i}\right)=1
\end{array}\right.
$$

We can obtain the steady state probability using on Equation (4):

$$
\begin{aligned}
& P Q=0, \\
& \sum_{i=0}^{k} P\left(M_{i}\right)=1, \\
& P=\left(P\left(M_{0}\right), P\left(M_{1}\right), \cdots, P\left(M_{k}\right)\right) .
\end{aligned}
$$

The above formula represents a row vector of the probability of steady states. The transferring matrix $Q=\left[q_{i j}\right],(0 \leq i, j \leq k), q_{i j}$ is defined as

$$
q_{i j}= \begin{cases}\lambda_{i j}, & i \neq j, \\ -\sum_{j=0}^{k} \lambda_{i j}, & \text { else. }\end{cases}
$$

Modeling the earthquake medical care process based on an SPN to define activities may lead to an increase in the delay time of the entire process and decrease in the efficiency. The 
busy probability of place indicator can be calculated using Equation (6). The utilization of a transition indicator can be calculated using Equation (7). In addition, the indicator of the system average delay time can be calculated using Equation $(8)^{[51]}$.

$$
\begin{aligned}
& P[M(p)=i]=\sum_{j} P\left[M_{j}\right], \quad M_{j} \in\left[M_{0}>M_{j}(p)=i,\right. \\
& U(t)=\sum_{M \in E} P[M] \\
& T=\frac{\overline{N_{i}}}{R(t, p)}=\frac{\sum_{j} j \times P\left[M\left(p_{i}\right)=j\right]}{W(t, p) U(t) \lambda} .
\end{aligned}
$$

\section{Case Study}

\subsection{Performance Analysis of Earthquake Medical Care Process Based on the SPN Model}

It is known that Sichuan Province frequently experiences earthquakes. We adopted the 512 Wenchuan Earthquake process to validate the proposed model. The Wenchuan Earthquake is the most critical and largest earthquake since the foundation of China and one of the largest scale earthquakes that mobilized the national medical rescue along with that of other provinces. The best recuse period is within $72 \mathrm{~h}$ after the earthquake occurrence. To facilitate the theoretical analysis, we assumed that the average time for the rescue program implementation was $72 \mathrm{~h}$. To facilitate the subsequent analysis, we assumed that the time of these transitions was based on an exponential distribution with $\lambda=10$ and $\lambda_{0}=10$. The time consumed by certain transitions was set based on the literature, experience and assumptions such as $\lambda_{8}=0.5$.

We collected information regarding the 512 Wenchuan Earthquake from various sources and a large amount of news corresponding to the earthquake at that time. We derived the average firing rate of 23 transitions based on which calculations were performed, and the results are as follows:

$$
\begin{gathered}
\lambda=(10,1,1,2,2,0,0,2,2,0,5,0,5,3,0,5,1,0.25,1,1, \\
0.0833,1,0.2,0.1429,0.0833,0.0833,0.0833,1) .
\end{gathered}
$$

According Equations (4), (6), (7), we can get the steady state probability, the busy probability of places, and the utilization of transitions, and they are shown in Table 3 , Table 4 , and Table 5, respectively.

In Table 4 , the busy probability of places such as $p_{8}$ is always high compared to others. This finding indicates that the information in these places cannot be processed in a timely manner, which results in information accumulation. $p_{7}, p_{16}, p_{20}$ and $p_{21}$ are the key factors that need to be optimized. 
Table 3 Steady state probability

\begin{tabular}{cccc}
\hline steady state probability & Data & steady state probability & Data \\
\hline$P\left(M_{0}\right)$ & 0.0030 & $P\left(M_{11}\right)$ & 0.0058 \\
$P\left(M_{1}\right)$ & 0.0304 & $P\left(M_{12}\right)$ & 0.0260 \\
$P\left(M_{2}\right)$ & 0.0101 & $P\left(M_{13}\right)$ & 0.0607 \\
$P\left(M_{3}\right)$ & 0.0051 & $P\left(M_{14}\right)$ & 0.0304 \\
$P\left(M_{4}\right)$ & 0.0202 & $P\left(M_{15}\right)$ & 0.1214 \\
$P\left(M_{5}\right)$ & 0.0152 & $P\left(M_{16}\right)$ & 0.0304 \\
$P\left(M_{6}\right)$ & 0.1518 & $P\left(M_{17}\right)$ & 0.0146 \\
$P\left(M_{7}\right)$ & 0.0152 & $P\left(M_{18}\right)$ & 0.0028 \\
$P\left(M_{8}\right)$ & 0.0304 & $P\left(M_{19}\right)$ & 0.1818 \\
$P\left(M_{9}\right)$ & 0.0043 & $P\left(M_{20}\right)$ & 0.1789 \\
$P\left(M_{10}\right)$ & 0.0304 & $P\left(M_{21}\right)$ & 0.0304 \\
\hline
\end{tabular}

Table 4 Busy probability of places

\begin{tabular}{cccc}
\hline Place & Data & Place & Data \\
\hline$P\left[M\left(p_{1}\right)=1\right]$ & 0.0030 & $P\left[M\left(p_{12}\right)=1\right]$ & 0.0101 \\
$P\left[M\left(p_{2}\right)=1\right]$ & 0.0304 & $P\left[M\left(p_{13}\right)=1\right]$ & 0.0969 \\
$P\left[M\left(p_{3}\right)=1\right]$ & 0.0303 & $P\left[M\left(p_{14}\right)=1\right]$ & 0.0867 \\
$P\left[M\left(p_{4}\right)=1\right]$ & 0.0203 & $P\left[M\left(p_{15}\right)=1\right]$ & 0.0304 \\
$P\left[M\left(p_{5}\right)=1\right]$ & 0.0152 & $P\left[M\left(p_{16}\right)=1\right]$ & 0.1214 \\
$P\left[M\left(p_{6}\right)=1\right]$ & 0.0354 & $P\left[M\left(p_{17}\right)=1\right]$ & 0.0304 \\
$P\left[M\left(p_{7}\right)=1\right]$ & 0.1518 & $P\left[M\left(p_{18}\right)=1\right]$ & 0.0146 \\
$P\left[M\left(p_{8}\right)=1\right]$ & 1.0000 & $P\left[M\left(p_{19}\right)=1\right]$ & 0.0028 \\
$P\left[M\left(p_{9}\right)=1\right]$ & 0.0152 & $P\left[M\left(p_{20}\right)=1\right]$ & 0.1818 \\
$P\left[M\left(p_{10}\right)=1\right]$ & 0.0608 & $P\left[M\left(p_{21}\right)=1\right]$ & 0.1798 \\
$P\left[M\left(p_{11}\right)=1\right]$ & 0.0607 & $P\left[M\left(p_{22}\right)=1\right]$ & 0.0304 \\
\hline
\end{tabular}

$p_{7}$ indicates the medical rescue scheduling information. Once a largescale earthquake occurs, it undoubtedly incurs a tremendous loss and leads to a larger demand for medical care resources. The government arranges for medical rescue teams according to the preliminary earthquake information. In addition, the onsite medical conductor provides feedback to the government, regarding the lack of resources. After receiving the information, the government decides the next steps. Both sides can easily incur information accumulation of medical rescue scheduling. Thus, it is necessary to focus on allocating rescue teams systematically to improve the efficiency of the rescue project. 
Table 5 Utilization of transitions

\begin{tabular}{cccc}
\hline Transition & Data & Transition & Data \\
\hline$U\left(t_{0}\right)$ & 0.0030 & $U\left(t_{12}\right)$ & 0.1214 \\
$U\left(t_{1}\right)$ & 0.0304 & $U\left(t_{13}\right)$ & 0.0304 \\
$U\left(t_{2}\right)$ & 0.0303 & $U\left(t_{14}\right)$ & 0.0146 \\
$U\left(t_{3}\right)$ & 0.0152 & $U\left(t_{15}\right)$ & 0.0146 \\
$U\left(t_{4}\right)$ & 0.0152 & $U\left(t_{16}\right)$ & 0.0146 \\
$U\left(t_{5}\right)$ & 0.1518 & $U\left(t_{17}\right)$ & 0.0028 \\
$U\left(t_{6}\right)$ & 0.0152 & $U\left(t_{18}\right)$ & 0.0028 \\
$U\left(t_{7}\right)$ & 0.0608 & $U\left(t_{19}\right)$ & 0.0028 \\
$U\left(t_{8}\right)$ & 0.0607 & $U\left(t_{20}\right)$ & 0.1818 \\
$U\left(t_{9}\right)$ & 0.0101 & $U\left(t_{21}\right)$ & 0.1796 \\
$U\left(t_{10}\right)$ & 0.0607 & $U\left(t_{22}\right)$ & 0.0304 \\
$U\left(t_{11}\right)$ & 0.0304 & & \\
\hline
\end{tabular}

$p_{16}$ represents the victims that have been rescued. Because of the abruptness and destructiveness of earthquakes, the victims are sent to the onsite clinic with no regular time or frequency. The medical resources are extremely limited and thus most victims only receive preliminary rescue. The primary task for medical workers is to try their best to save the lives of the wounded in the rescue site and provide an opportunity for their further treatments. Furthermore, not delivering the victims in the onsite clinic to other hospitals is a major reason for the places to be extremely busy. Therefore, in addition to ensuring the adequacy of the medical resources and medical staff, it is necessary to train professional teams that are in charge of transporting the victims. In a complex situation, such staff can deliver the victims to a general hospital near the disaster area, which is a significant step in relieving the pressure of onsite clinics and ensuring the safety of the transportation.

$p_{20}$ and $p_{21}$ respectively represent the information regarding the acceptance of the victims in the hospitals situated in and outside the province. Considering an increase in the number of victims, the situation of preliminary rescue and the utilization of medical resources, the medical conductor may consider classifying the victims into different groups and clarifying the method of transportation. According to our study, the scale of the transportation of victims during the Wenchuan earthquake is one of the largest ever witnessed in the history of China.

The busy probabilities of the two places are somewhat large partly because it is the first time such a large number of victims are being transported and sufficient experience is not present to manage this situation efficiently. In particular, the staff in charge of transporting the victims are usually medical workers who may have professional clinical skills but lack the practical experience when faced with a complicated situation after a largescale earthquake occurs for the first time. In addition, the secondary classification of the wounded is also insufficient in hospitals situated in the disaster area. In addition, no treatment network exists between the large 
hospitals in and outside the province and general hospitals. The above reasons are all likely to cause the busy probability of places to accumulate. To cope with serious disasters in the future, the government needs to formulate improvement projects regarding the selection of casualties and refining the work of the transportation process. Training professional transporting teams not only help them acquire clinical medical knowledge but also contribute to their accumulation of practical experience in emergencies.

As shown in Table 5 , the utilization of transitions such as $t_{5}, t_{12}, t_{20}, t_{21}$, is considerably higher than that of the others, which means that the former transitions are relatively time consuming. $t_{5}$ represents the launch of medical rescue and search teams. Timeliness is a crucial factor for the victims in danger of losing lives. $t_{12}$ represents the transportations of the victims to a general hospital near the disaster area, which also highlights timeliness. Faced with an unfavorable medical rescue environment, heavy tasks and extreme pressure, the medical staff can administer only simple first aid treatment without any advanced equipment. To achieve more time for the overall treatment of the wounded, the staff responsible for transporting the victims must improve the efficiency of transportation. However, timeliness is not the primary factor for transitions. Instead, the focus should be more on rescuing the wounded comprehensively and thoroughly and reducing the side effects of the earthquake occurrence on the victims, as indicated by $t_{20}$ and $t_{21}$.

The system average delay time can be calculated using Equation (8)

$$
T=\frac{\overline{N_{i}}}{R(t, p)}=\frac{2.2084}{1 \times 0.0030 \times 10}=73.6 \mathrm{~h} .
$$

The subsystem concerning the preparatory phase average delay time $\left(p_{1}-p_{7}\right)$ is

$$
T=\frac{\overline{N_{i}}}{R(t, p)}=\frac{0.2864}{0.030}=9.55 \mathrm{~h} .
$$

The subsystem concerning the average delay time $\left(p_{8}-p_{22}\right)$ is

$$
T=\frac{\overline{N_{i}}}{R(t, p)}=\frac{1.922}{1 \times 0.1518 \times 0.2}=63.3 \mathrm{~h} .
$$

The calculated average delay time of the complete system is larger primarily because, in the SPN model, a conflict occurs in the post situation and the considered situation. However, when the average delay time of the entire system was calculated, all such actions were considered. Thus, the actual time was less than $73.6 \mathrm{~h}$, which is approximately the golden rescue time. This finding proves the validity of the model.

\subsection{Simulation Analysis of Earthquake Medical Rescue Process}

We considered the Wenchuan earthquake as an example in the simulation analysis as well. Subsection 4.1 corresponded to the performance analysis for the Wenchuan earthquake medical process; the busy places and high utilization of transitions in the medical care process were identified, and improvement measures were suggested. In this analysis, we modified some critical transitions and calculated the corresponding time of the whole medical system. To 
determine the transitions that could reduce the time taken by the medical rescue system, we adopted measures that could accelerate the transitions. Finally, the Matlab software was used to obtain the schematics regarding the effect of the steady state probability of the complete system when one of the critical transitions changed within a certain range.

Because different transitions represent different behaviors, we did not set the same range of speed and computed the corresponding system time according to the actual situation of every transition. However, as the result shows, no trend exists that demonstrates that a higher speed leads to shorter medical system time. Instead, the best transition speed leads to the shortest system time. Because of the different scope of transitions, we proposed that the time reduction of the entire system was dependent on the unit speed of the transition change, rather than the acceleration of different transitions influencing the proposed medical system.

Assuming that the value of $\lambda_{i}$ is $[a, b], a$ and $b$ respectively represent the smallest and largest speeds of the transition. $\frac{b-a}{n}(n \geqslant 4)$ is used to obtain a few sets of values and calculate some sets of medical system time based on Formula (5) described in Subsection 3.2. For $a \leq x_{1} \leq x_{2} \leq b$, when $\lambda_{i}=x_{1}, T=t_{1}$ and when $\lambda_{i}=x_{2}, T=t_{2}$. If $\left|t_{1}-t_{2}\right| \leq 0.5, x_{2}$ is deleted. The expression for the total time of the system change at the unit transition speed is $\sigma=\left|\frac{T_{i}^{1}-T_{i}^{2}}{\lambda_{i}^{1}-\lambda_{i}^{2}}\right|$, when $\lambda_{i}^{1}$ and $\lambda_{i}^{2}$ represent the two types of speed of one transition, and $T_{i}^{1}$ and $T_{i}^{2}$ represent the total time of the system. Thus, we calculated the change in the value for the medical rescue system under the value of every transition unit, as presented in Table 6 .

As shown in Table $6, \lambda_{7}, \lambda_{12}, \lambda_{8}, \lambda_{5}, \lambda_{11}$ are the five most effective transitions compared to the others. Further analysis regarding these transitions was performed using the Matlab software to obtain schematics pertaining to the effect of steady state probability of the complete system when one of the critical transitions changed within a certain range.

Table 6 Changed value of system total time under changed unit transition speed

\begin{tabular}{cccc}
\hline Transition & Unit value & Transition & Unit value \\
\hline$\lambda_{7}$ & 26.12 & $\lambda_{1}$ & 4.64 \\
$\lambda_{12}$ & 20.10 & $\lambda_{13}$ & 3.07 \\
$\lambda_{8}$ & 18.12 & $\lambda_{14}$ & 2.34 \\
$\lambda_{5}$ & 12.11 & $\lambda_{6}$ & 1.82 \\
$\lambda_{11}$ & 9.67 & $\lambda_{4}$ & 1.45 \\
$\lambda_{2}$ & 9.15 & $\lambda_{15}$ & 0.90 \\
$\lambda_{10}$ & 8.79 & $\lambda_{0}$ & 0.57 \\
$\lambda_{9}$ & 6.44 & $\lambda_{17}$ & 0.008 \\
$\lambda_{3}$ & 6.42 & $\lambda_{18}$ & 0.0075 \\
$\lambda_{16}$ & 4.68 & & \\
\hline
\end{tabular}

Scenario 1 involved changing the value of $\lambda_{5}$ (the response speed of emergency search and medical rescue teams). 
We assumed that the values of $\lambda_{0}, \lambda_{1}, \cdots, \lambda_{4}, \lambda_{6}, \cdots, \lambda_{22}$ remained unchanged (the value of these transitions have been provided in Subsection 4.1) and the value of $\lambda_{5}$ was changed. The results are provided in Figure 4. Figure 4 shows that when the value of $\lambda_{5}$ varies from 0.2 to 5 ,which implies an increase in the response rate of $\lambda_{5}$, the probability of $P\left(M_{6}\right)$ decreases considerably. This aspect indicates that people trapped in the disaster area can be rescued if the conductor can arrange rescue resources as soon as possible after the occurrence of the earthquake. To increase the speed of the rescue teams entering the disaster area considering the unreasonably scheduled project, the government must commit to daily management and train emergency medical care teams. In addition, medical care channels dealing with emergencies must be established and advanced medical facilities must be purchased or invented. The aim of the steps suggested above is to decrease the probability of accumulation of the medical rescue scheduling information.

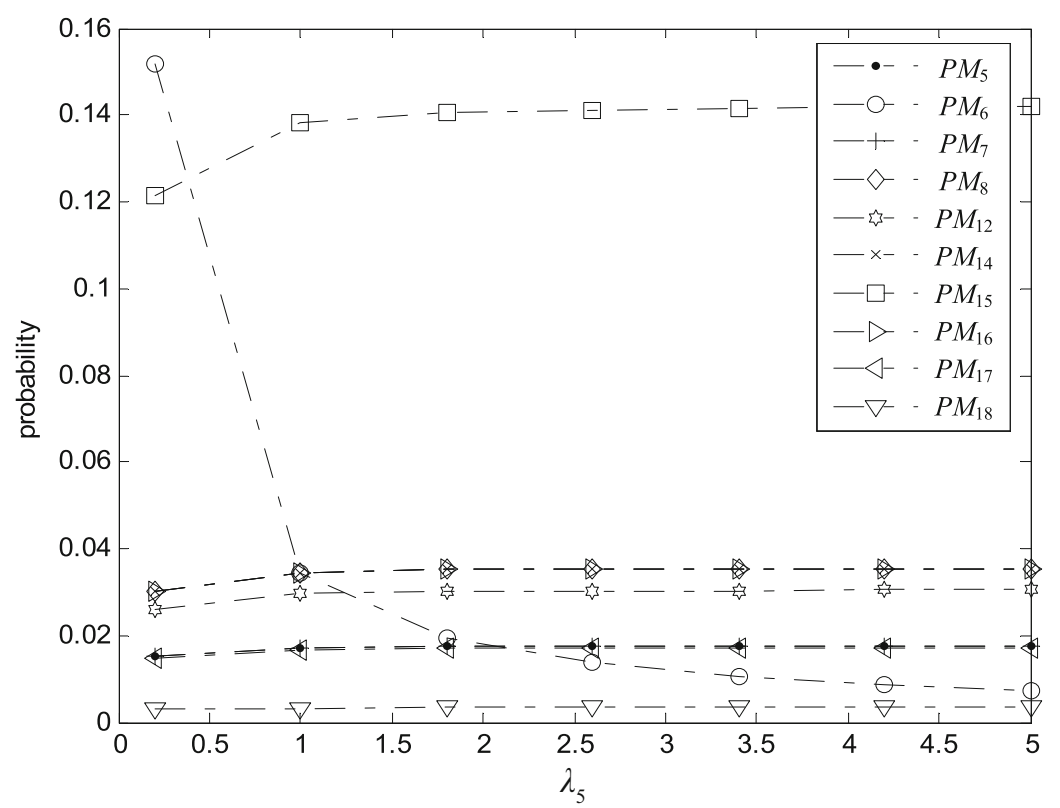

Figure 4 Variation of system probability with change in $\lambda_{5}$

Scenario 2 involved changing the value of $\lambda_{7}$ (the onsite searching speed).

The staff is responsible for saving the victims from the debris and delivering them to the onsite clinic, the speed of which is critical for the victims to be rescued. We assumed that $\lambda_{0}, \lambda_{1}, \cdots, \lambda_{6}, \lambda_{8}, \lambda_{9}, \cdots, \lambda_{22}$ are constant, and changed $\lambda_{7}$ from 0.1 to 6 . As shown in Figure 5, if the speed of the search teams saving people trapped in the debris increases, the probability of accumulation of the victims in the onsite clinic $P\left(M_{12}\right)$ also increases. This finding suggests that it is important to improve the speed of saving people from the debris. In addition, it is also necessary to identify whether the medical rescue resources are lacking. In the case of insufficient medical resources and adverse conditions in the onsite clinic, the key task is to conduct a preliminary diagnosis and administer first aid treatment orderly and efficiently when a large number of victims are present; otherwise, it may lead to accumulation of the victims. 


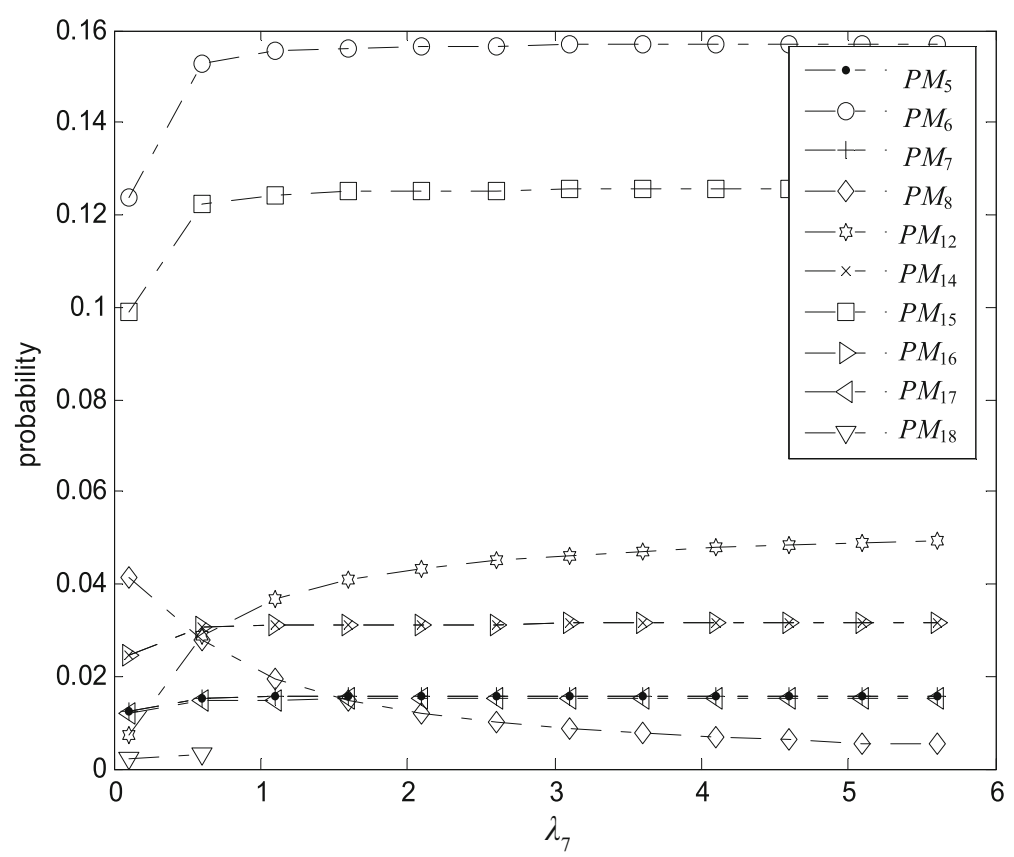

Figure 5 Variation of system probability with change in $\lambda_{7}$

It can also be noted that the probability of medical rescue resources entering the disaster area $P\left(M_{8}\right)$ decreases; in particular, the rescuers are busy in handling the onsite rescue task when rapidly processing the onsite search. Thus, it is necessary to provide the feedback regarding medical rescue information to the supervisors. A combination of sending new rescue resources to the disaster area and completing tasks effectively in the temporary onsite clinic can facilitate the onsite searching process. However, information communication is key to realize the medical rescue. Maintaining unblocked information delivery can help the external disaster areas, onsite medical staff and temporary clinic establish cooperation and increase the survival rate of victims.

Scenario 3 involved changing the value of $\lambda_{8}$ (the speed of setting up the onsite clinic).

We assumed that the values of $\lambda_{0}, \lambda_{1}, \cdots, \lambda_{7}, \lambda_{9}, \cdots, \lambda_{22}$ remained unchanged, and the value of $\lambda_{8}$ was changed from 0.2 to 2 ; the results are shown in Figure 6. In Figure 6, when the value of $\lambda_{8}$ is increasing, specifically, the speed of setting up a temporary clinic is increasing, the probabilities $P\left(M_{8}\right)$ and $P\left(M_{12}\right)$ are decreasing. Setting up a temporary clinic is a common but necessary measure, which is urgently required for the severely injured people to receive urgent treatment in the earthquake onsite area. The clinic not only provides the victims with prompt treatment but also relieves the pressure on transportation. Three criteria exist for setting up a temporary clinic: Minor effects of the aftershocks, the shortest route from each disaster area and a safe and clean site to administer treatment conveniently. 


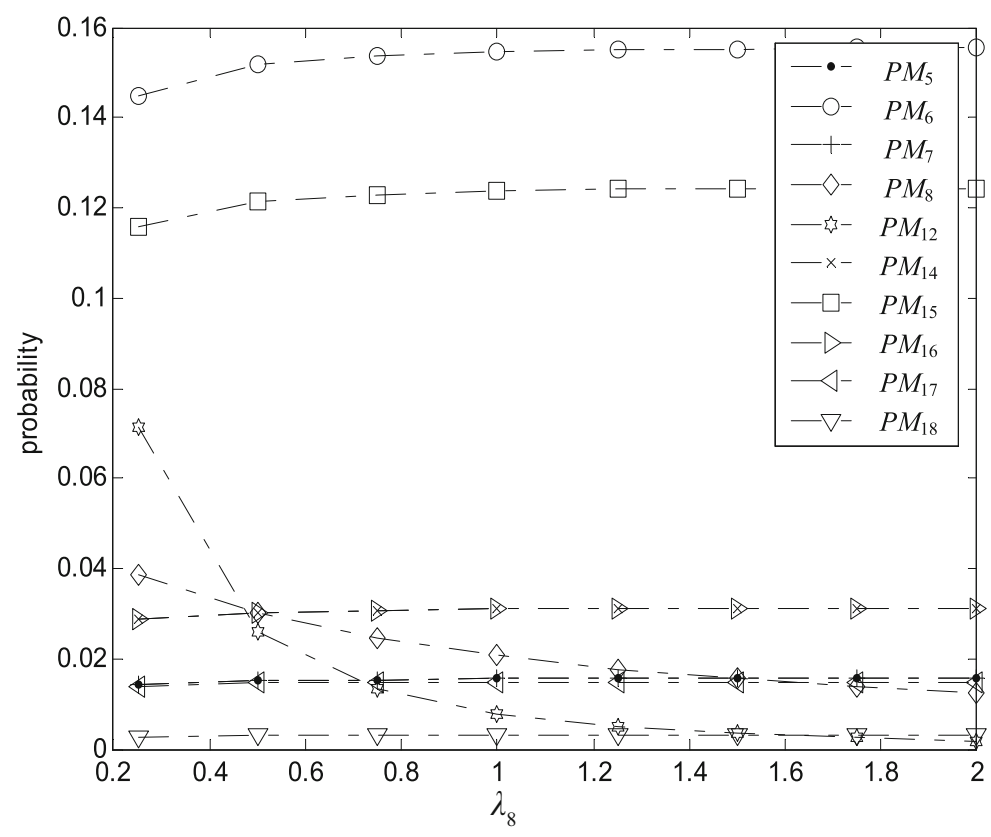

Figure 6 Variation of system probability with change in $\lambda_{8}$

Scenario 4 involved changing the value of $\lambda_{11}$ (the speed of rescuing the victims in the disaster area).

We assumed that the values of $\lambda_{0}, \lambda_{1}, \cdots, \lambda_{10}, \lambda_{12}, \cdots, \lambda_{22}$ remained unchanged, and the value of $\lambda_{11}$ was changed; the results are shown in Figure 7 .

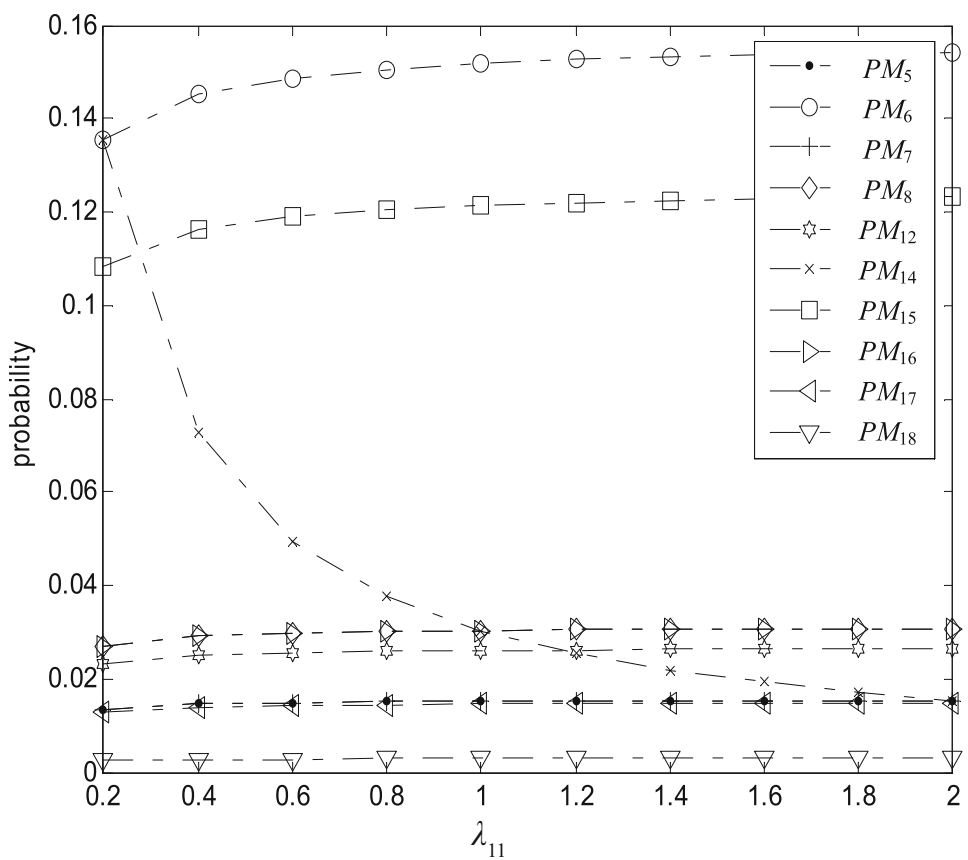

Figure 7 Variation of system probability with change in $\lambda_{11}$ 
In Figure 7, when the value of $\lambda_{11}$ varies from 0.2 to 2, the speed of rescuing the victims in the disaster area increases, and the probability of accumulation of the victims after classification $P\left(M_{14}\right)$ decreases. Because the medical rescue staff increases the speed of onsite rescue, several victims are provided with treatment and delivered to hospitals from the onsite clinic. The pressure of accommodating victims in the temporary clinic is alleviated. At the same time, the probability of $P\left(M_{16}\right)$ increases, specifically, the probability of accumulation of the schedule information of medical rescue and feedback information are increasing. In this case, medical rescue resources must be urgently supplied, and the supervisor must be informed regarding the victims health conditions in a timely manner. The most critical difficulty in a disaster area is the occurrence of poor communication or even paralyzed communication. If we persist in accelerating onsite rescue, a chaotic scene may occur. For example, some staff may not take notes regarding the victims basic information and ensure a timely delivery arrangement. Therefore, after the occurrence of an earthquake, effective information delivery and cooperation between external and internal disaster areas are key to ensure a smooth subsequent rescue. So it is necessary to design a resilient system to prevent the communication disruption when the occurrence of an earthquake.

Scenario 5 involved changing the value of $\lambda_{12}$ (the speed of delivering victims to general hospitals near the disaster area).

We assumed that the values of $\lambda_{0}, \lambda_{1}, \cdots, \lambda_{11}, \lambda_{13}, \cdots, \lambda_{22}$ remained unchanged, and the value of $\lambda_{12}$ was changed from 0.1 to 1 ; the results are shown in Figure 8.

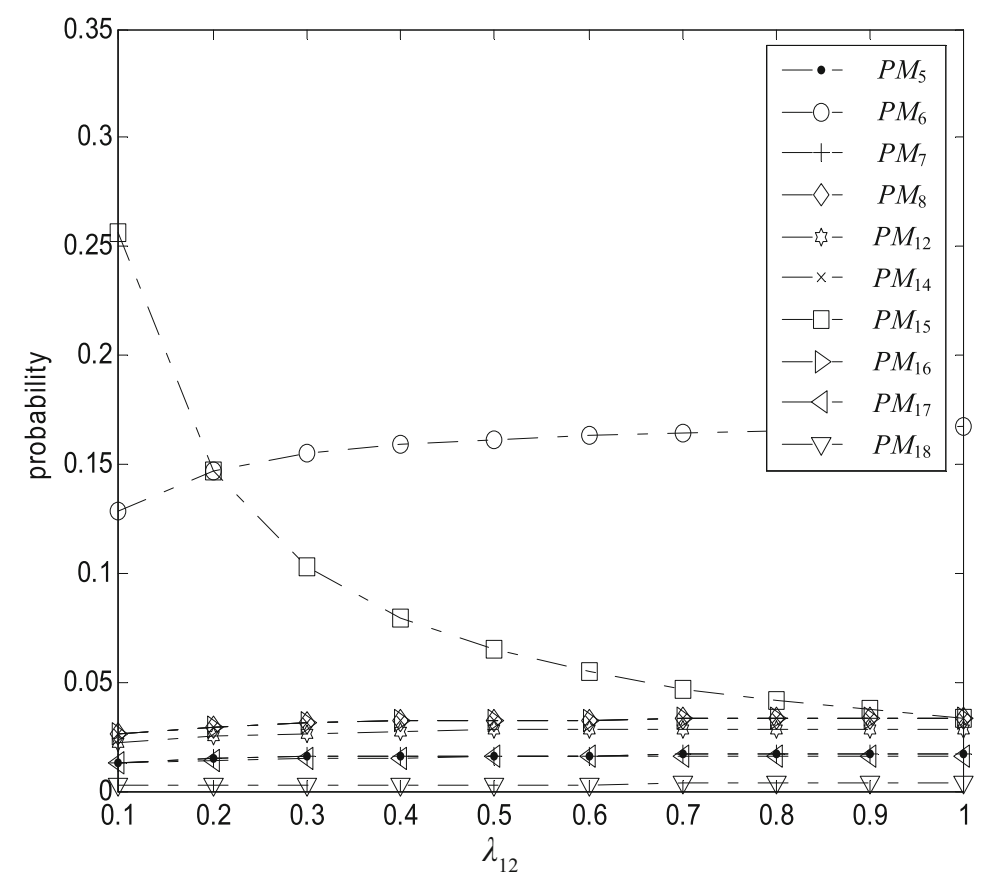

Figure 8 Variation of system probability with change in $\lambda_{12}$

In Figure 8, when $\lambda_{12}$, which is the speed of delivering victims to general hospitals near the 
disaster area is increasing, the probability of $P\left(M_{15}\right)$ is decreasing. The capacity and medical resources in the temporary clinic are limited, but the quantity of victims far exceed its capacity. Generally, measures are adopted to deliver victims to the rear hospitals. During the rear delivery process, along with the sufficiency of medical rescue staff and resources, close cooperation among hospitals of different levels and effective and safe logistic transportation should be focused on. The government of China facilitates green channels and highly stresses the protection of victims during the transportation process to avoid aggravating the injury conditions. To ensure that the above measures can be implemented successfully, training rescue staff in daily life is required. Hospitals situated in areas that are frequently struck by earthquakes should enforce cooperation with hospitals of different levels and participate in earthquake exercises in daily life. In this manner, emergencies such as occurrences of earthquakes can be effectively managed.

\section{Conclusions and Limitations}

\subsection{Conclusions}

In this paper, we proposed a method to model and simulate the earthquake EMR process based on SPN. To validate the proposed method, we applied the Petri net method to the Wenchuan earthquake case in China. The proposed model could evaluate the entire system and the expressions of the steady state probabilities of this system under various states are obtained based on the MC. We found the five transitions that most considerably influence our medical system, they are onsite searching, transporting the victims to the general hospital near the disaster area, setting up the onsite clinic, launching emergency search and rescue teams, administering first aid treatment in the disaster area. In all critical transitions, the launching of emergency search and rescue teams to the disaster area and transporting the victims are the most time-consuming transitions. It is suggested that professional medical emergency rescue teams must be organized and trained before an earthquake occurs. And the EMR teams should be trained by actual or simulation exercises to enhance their responsiveness. Another problem is transportation in the emergency rescue process. The government should set up the emergency transportation operations office to coordinate water-land-air traffic under the adverse conditions in disaster areas such as extreme damage to road communication facilities and invalid equipment. The government must purchase advanced medical facilities and transportation equipment and strengthen the cooperation between delivery organizations and hospitals.

\subsection{Limitations and Further Work}

The performance analysis of the medical rescue process is a highly complicated problem. Our study also includes certain shortcomings, such as in the average firing rate of transitions. The processing of the collected data regarding the Wenchuan earthquake is not precise owing to the time span and the digital unit not being totally consistent. To perform the analysis using a stochastic Petri net, we considered the reciprocal of the time as the firing rate of the transitions. In addition, we did not consider the problems of material dispatching and the hysteresis of material transportation, which might prevent a rescue process from being implemented. The 
above points will be focused on in a further study.

\section{References}

[1] Wu D D and Olson D L, Introduction to the special section on Chinese earthquake risk management, Human and Ecological Risk Assessment, 2010, 16(3): 454-462.

[2] Liu Y, Wei J, Xu J, et al., Evaluation of the moderate earthquake resilience of counties in China based on a three-stage DEA model, Natural Hazards, 2018, 91(2): 587-609.

[3] Lu-Ping Z, Rodriguez-Llanes J M, Qi W, et al., Multiple injuries after earthquakes: A retrospective analysis on 1, 871 injured patients from the 2008 Wenchuan earthquake, Critical Care, 2012, 16(3): R87.

[4] Li X, Li Z, Yang J, et al., Spatiotemporal characteristics of earthquake disaster losses in China from 1993 to 2016, Natural Hazards, 2018, 94(2): 843-865.

[5] Lei H, Wang X, Hou H, et al., The earthquake in Jiuzhaigou County of Northern Sichuan, China on August 8, 2017, Natural Hazards, 2018, 90(2): 1021-1030.

[6] Zhang H, What has China learnt from disasters? Evolution of the emergency management system after SARS, Southern Snowstorm, and Wenchuan Earthquake, Journal of Comparative Policy Analysis: Research and Practice, 2012, 14(3): 234-244.

[7] Zhang Y, Weng W G, and Huang Z L, A scenario-based model for earthquake emergency management effectiveness evaluation, Technological Forecasting and Social Change, 2018, 128: 197-207.

[8] Chu X and Zhong Q, Post-earthquake allocation approach of medical rescue teams, Natural Hazards, 2015, 79(3): 1809-1824.

[9] Huang Y, Modeling and simulation method of the emergency response systems based on OODA Knowledge-Based Systems, 2015, 89: 527-540.

[10] Mohammadi R, Ghomi S F, and Jolai F, Prepositioning emergency earthquake response supplies: A new multi-objective particle swarm optimization algorithm, Applied Mathematical Modelling, 2016, 40(9-10): 5183-5199.

[11] Rong H, Xuedong L, Guizhi Z, et al., An evaluation of coordination relationships during earthquake emergency rescue using entropy theory, Cadernos de Saude Publica, 2015, 31: 947-959.

[12] Xie X, Li J, Swartz C H, et al., Modeling and analysis of ward patient rescue process on the hospital floor, IEEE Transactions on Automation Science and Engineering, 2016, 13(2): 514-528.

[13] He Z, Wu Q, Wen L, et al., A process mining approach to improve emergency rescue processes of fatal gas explosion accidents in Chinese coal mines, Safety Science, 2019, 111: 154-166.

[14] Khan S A, Zafar N A, Ahmad F, et al., Extending Petri net to reduce control strategies of railway interlocking system, Applied Mathematical Modelling, 2014, 38(2): 413-424.

[15] Fecarotti C, Andrews J, and Chen R, A Petri net approach for performance modelling of polymer electrolyte membrane fuel cell systems, International Journal of Hydrogen Energy, 2016, 41(28): 12242-12260.

[16] Bahl A, Sachdeva A, and Garg R K, Availability analysis of distillery plant using Petri nets, International Journal of Quality \& Reliability Management, 2018, 35(10): 2373-2387.

[17] Meyer J F, Movaghar A, and Sanders W H, Stochastic activity networks: Structure, behavior, and application, International Workshop on Timed Petri Nets, 1985, July: 106-115. 
[18] Subramaniam C, Ali H, and Mohd Shamsudin F, Understanding the antecedents of emergency response: A proposed framework, Prevention and Management: An International Journal, 2010, 19(5): 571-581.

[19] Lu Y and Xu J, The progress of emergency response and rescue in China: A comparative analysis of Wenchuan and Lushan earthquakes, Natural Hazards, 2014, 74(2): 421-444.

[20] Chen A, Chen N, and Li J, During-incident process assessment in emergency management: Concept and strategy, Safety Science, 2012, 50(1): 90-102.

[21] Huang Y, Modeling and simulation method of the emergency response systems based on OODA, Knowledge-Based Systems, 2015, 89: 527-540.

[22] Vivacqua A S and Borges M R, Taking advantage of collective knowledge in emergency response systems, Journal of Network and Computer Applications, 2012, 35(1): 189-198.

[23] Gunawan L T, Alers H, Brinkman W P, et al., Distributed collaborative situation-map making for disaster response, Interacting with Computers, 2011, 23(4): 308-316.

[24] Bevilacqua M, Ciarapica F E, and Paciarotti C, Business process reengineering of emergency management procedures: A case study, Safety Science, 2012, 50(5): 1368-1376.

[25] Liu J, Zhou H, and Sun H, A three-dimensional risk management model of port logistics for hazardous goods, Maritime Policy \& Management, 2019, 46(6): 715-734.

[26] Nivolianitou Z and Synodinou B, Towards emergency management of natural disasters and critical accidents: The Greek experience, Journal of Environmental Management, 2011, 92(10): 26572665.

[27] De Oliveira M and Toscano L, An integrated emergency care delivery system for major events, Operations Research for Health Care, 2018, 17: 16-27.

[28] Chen A and Yu T, Network based temporary facility location for the Emergency Medical Services considering the disaster induced demand and the transportation infrastructure in disaster response, Transportation Research Part B: Methodological, T. Y., 2016, 91: 408-423.

[29] Galvagno S, Haut E, Zafar S, et al., Association between helicopter vs ground emergency medical services and survival for adults with major trauma, Jama, 2012, 307(15): 1602-1610.

[30] Andruszkow H, Lefering R, Frink M, et al., Survival benefit of helicopter emergency medical services compared to ground emergency medical services in traumatized patients, Critical Care, 2013, 17(3): R124.

[31] Abe T, Takahashi O, Saitoh D, et al., Association between helicopter with physician versus ground emergency medical services and survival of adults with major trauma in Japan, Critical Care, 2014, 18(4): R146.

[32] Shan S, Wang L, and Li L, Modeling of emergency response decision-making process using stochastic Petri net: An e-service perspective, Information Technology and Management, 2012, 13(4): 363-376.

[33] Wang J, Ip W, Muddada R, et al., On Petri net implementation of proactive resilient holistic supply chain networks, The International Journal of Advanced Manufacturing Technology, 2013, 69(1-4): 427-437.

[34] Li Z, Liu G, Hanisch H, et al., Deadlock prevention based on structure reuse of Petri net supervisors for flexible manufacturing systems, IEEE Transactions on Systems, Man, and CyberneticsPart A: Systems and Humans, 2012, 42(1): 178-191.

[35] $\mathrm{Hu} \mathrm{H}$ and Zhou M, A Petri net-based discrete-event control of automated manufacturing systems with assembly operations, IEEE Transactions on Control Systems Technology, 2015, 23(2): 513- 
524.

[36] Zhou J and Genserik R, Petri-net based modeling and queuing analysis for resource-oriented cooperation of emergency response actions, Process Safety and Environmental Protection, 2016, 102(6): $567-576$.

[37] Liu C, Zeng Q, Duan H, et al., E-net modeling and analysis of emergency response processes constrained by resources and uncertain durations, IEEE Transactions on Systems, Man, and Cybernetics: Systems, 2014, 45(1): 84-96.

[38] Liu R, Kumar A, and Van Der Aalst W, A formal modeling approach for supply chain event management, Decision Support Systems, 2007, 43(3): 761-778.

[39] Liu C, Zeng Q, Duan H, et al., E-net modeling and analysis of emergency response processes constrained by resources and uncertain durations, IEEE Transactions on Systems, Man, and Cybernetics: Systems, 2015, 45(1): 84-96.

[40] Nie H, Tang S Y, et al., Triage during the week of the Sichuan earthquake: A review of utilized patient triage, care, and disposition procedures, Injury, 2011, 42(5): 515-520.

[41] Chen J, Zhao W, Xian M, et al., Transprovince transfer of 10, 373 patients injured in Wenchuan Earthquake, Journal of Evidence Based Medicine, 2009, 2(4): 270-276.

[42] Xiang B, Cheng W, Liu J, et al., Triage of pediatric injuries after the 2008 Wen-Chuan earthquake in China, Journal of Pediatric Surgery, 2009, 44(12): 2273-2277.

[43] Zhang L, Liu Y, Liu X, et al., Rescue efforts management and characteristics of casualties of the Wenchuan earthquake in China, Emergency Medicine Journal, 2011, 28(7): 618-622.

[44] Zhang L, Liu X, Li Y, et al., EMR efforts after a major earthquake: Lessons from the 2008 Wenchuan earthquake, The Lancet., 2012, 379(9818): 853-861.

[45] Chen A Y and Yu T Y, Network based temporary facility location for the emergency medical services considering the disaster induced demand and the transportation infrastructure in disaster response, Transportation Research Part B: Methodological, 2016, 91: 408-423.

[46] Vautherin J and Memmi G, Computation of flows for unary-predicates/transitions-nets, Ed. by Rozenberg G, Advances in Petri Nets, Springer, New York, 1985.

[47] Zhao H and Luo S, Modeling and analysis of reverse supply chain based on generalized stochastic Petri nets, International Conference on Information Management, Innovation Management and Industrial Engineering IEEE, 2009.

[48] Lin C, Stochastic Petri Net and System Performance Evaluation, Tsinhua University, Beijing, 2005.

[49] Molloy M K, Performance analysis using stochastic Petri net, IEEE Transactions on Computers, 1982, (9): 913-917.

[50] Finkel A and Leroux J, Recent and simple algorithms for Petri nets, Software \& Systems Modeling, 2015, 14(2): 719-725.

[51] Ma Z, Li Z, and Giua A, Design of optimal Petri net controllers for disjunctive generalized mutual exclusion constraints, IEEE Transactions on Automatic Control, 2015, 60(7): 1774-1785. 